\title{
4-Acetoxydolastane Diterpene from the Brazilian Brown Alga Canistrocarpus cervicornis as Antileishmanial Agent
}

\author{
Adriana Oliveira dos Santos ${ }^{1}$, Elizandra Aparecida Britta ${ }^{2}$, Everson Miguel Bianco ${ }^{3}$, \\ Tania Ueda-Nakamura ${ }^{2}$, Benedito Prado Dias Filho ${ }^{1,2}$, Renato Crespo Pereira ${ }^{4}$ and \\ Celso Vataru Nakamura ${ }^{1,2, *}$
}

1 Postgraduate Program in Microbiology, State University of Londrina, Highway Celso Garcia Cid, PR 445, Km 380, CEP 86051-990, Londrina, Parana, Brazil;

E-Mails: oi_dri@hotmail.com (A.O.d.S.); bdpfilho@uem.br (B.P.D.F.)

2 Postgraduate Program in Pharmaceutical Sciences, Laboratory of Technological Innovation in the Development of Drugs and Cosmetics, State University of Maringa, Colombo Avenue 5790, CEP 87020-900, Maringa, Parana, Brazil; E-Mails: elizandrabritta@hotmail.com (E.A.B); tunakamura@uem.br (T.U.-N.)

3 Postgraduate Program in Chemistry, Department of Fundamental Chemistry, Federal University of Pernambuco, CEP 50670-901, Recife, Pernambuco, Brazil; E-Mail: ebianco@chemist.com Department of Marine Biology, Federal Fluminense University, PO Box 100644, CEP 24001-970, Niteroi, Rio de Janeiro, Brazil; E-Mail: egbrecp@vm.uff.br

* Author to whom correspondence should be addressed; E-Mail: cvnakamura@uem.br; Tel.: +55-44-3011-5012; Fax: +55-44-3011-5046.

Received: 14 September 2011; in revised form: 1 October 2011 / Accepted: 18 October 2011 / Published: 11 November 2011

\begin{abstract}
Natural marine products have shown an interesting array of diverse and novel chemical structures with potent biological activities. Our study reports the antiproliferative assays of crude extracts, fraction and pure compound $(4 R, 9 S, 14 S)-4 \alpha$-acetoxy- $9 \beta, 14 \alpha$ dihydroxydolast-1(15),7-diene (1) obtained from brown alga Canistrocarpus cervicornis showing the antileishmanial activity. We showed that $\mathbf{1}$ had a dose-dependent activity during $72 \mathrm{~h}$ of treatment, exhibiting $\mathrm{IC}_{50}$ of $2.0 \mu \mathrm{g} / \mathrm{mL}, 12.0 \mu \mathrm{g} / \mathrm{mL}$, and $4.0 \mu \mathrm{g} / \mathrm{mL}$ for promastigote, axenic amastigote and intracellular amastigote forms of Leishmania amazonensis, respectively. A cytotoxicity assay showed that the action of the isolated compound 1 was 93.0 times less toxic to the macrophage than to the protozoan. Additionally, compound $\mathbf{1}$ induced ultrastructural changes, including extensive mitochondrial damage; decrease in Rh123 fluorescence, suggesting interference with the
\end{abstract}


mitochondrial membrane potential; and lipid peroxidation in parasite cells. The use of $\mathbf{1}$ from $C$. cervicornis against $L$. amazonensis parasites might be of great interest as a future alternative to the development of new antileishmanial drugs.

Keywords: antileishmanial activity; Leishmania amazonensis; Canistrocarpus cervicornis

\section{Introduction}

Human leishmaniasis is an endemic parasitic disease which represents a major health problem in the tropical and subtropical regions of the world. The prevalence is 12 million people and the overall population at risk is 350 million people [1].

Leishmaniasis is caused by a species of the Leishmania, a flagellated protozoan from the Trypanosomatidae family. The disease is transmitted by the bite of a sandfly which belongs to Lutzomia genus. Parasites of the Leishmania sp. have a heteroxenic life cycle that includes an intracellular amastigote form within the mononuclear phagocytes in mammal hosts and an extracelular promastigote form in vector insects [2,3].

Leishmaniasis is classified in four distinct clinical forms, visceral (VL), cutaneous (CL), difuse cutaneous (DCL) and mucocutaneous leishmaniasis (MCL) [4]. The clinical manifestations depend on the parasite species and the susceptibility of the host. The therapy is very complicated because the drugs for the treatment have many limitations and Leishmania species have already presented resistence to the drugs [2]. Pentavalent antimonials have been used for leishmaniasis treatment for more than 50 years. However, they cause serious side effects, such as cardiac and renal toxicity, as well as continuing to require long-term treatment. Other alternative drugs to antimonials in unresponsive cases are: Pentamidine and amphotericin B. Unfortunately, these drugs also cause toxic effects [5,6].

Bioactive natural products have been isolated from marine organisms and their pharmacological properties analyzed [7]. For example, brown algae produce a range of these compounds that have a wide variety of ecological functions such as defense against herbivores [8], fouling [9,10] and pathogenic microbes [11]. They also display a wide spectrum of pharmacological properties, such as antiviral [12], antiprotozoa [13,14], antibacterial [15], antioxidant [16] and anticoagulant [17].

A variety of different dolastane and seco-dolastanes diterpenes have been isolated from the brown marine macroalga Canistrocarpus cervicornis (formerly Dictyota cervicornis) [10,18-21]. In this study the leishmanicidal activity of crude extracts, fraction, and a 4-acetoxy-dolastane diterpene (1) obtained from $C$. cervicornis were first measured in laboratory assays against the Leishmania amazonensis.

\section{Results and Discussion}

Marine brown algae of the family Dictyotaceae are rich sources of monocyclic, bicyclic, and tryciclic diterpenes as major secondary metabolites [18,22-26]. Interestingly, this seaweed has a wide distribution along the Brazilian coast [25]. This traditional medicine still plays an important role in primary health care [27]. Plant-derived drugs remain an important resource, especially in developing 
countries, in combating diseases [6]. This is particularly true for marine natural products, which show an interesting array of diverse and novel chemical structures with potent biological activities [28].

Our study reports the antiproliferative assays of crude extracts (EACE, MCE and DCE), fraction (EAF) and pure compound (1) $(4 R, 9 S, 14 S)$-4 $\alpha$-acetoxy-9 $\beta, 14 \alpha$-dihydroxydolast-1(15),7-diene (Figure 1) obtained from brown alga $C$. cervicornis showing the dose-dependent effect against promastigote forms of L. amazonensis (Figures 2 and 3). In Table 1, we have demonstrated the concentrations values of crude extracts, fraction, and 1 that inhibited $50 \%$ of this parasite $\left(\mathrm{IC}_{50}\right.$ values) after $72 \mathrm{~h}$ of incubation. Thus, the $\mathrm{IC}_{50}$ of crude extracts EACE, MCE and DCE were $50.0 \mu \mathrm{g} / \mathrm{mL}$, $100.0 \mu \mathrm{g} / \mathrm{mL}$ and $20.0 \mu \mathrm{g} / \mathrm{mL}$, respectively. The $\mathrm{IC}_{50}$ of fraction (EAF) and 1 were $8.0 \mu \mathrm{g} / \mathrm{mL}$ and $2.0 \mu \mathrm{g} / \mathrm{mL}$, respectively. The student's $t$ test $(p<0.05)$ indicated significant differences between crude extracts, fraction and isolated compounds compared to the control group. In addition, amphotericin B showed $\mathrm{IC}_{50}$ of $0.06 \mu \mathrm{g} / \mathrm{mL}$ against promastigote forms after $72 \mathrm{~h}$ of treatment.

Figure 1. Chemical structure of compound $1(4 R, 9 S, 14 S)$ - $4 \alpha$-acetoxy-9 $\beta, 14 \alpha$-dihydro xydolast-1(15),7-diene, isolated from Canistrocarpus cervicornis.

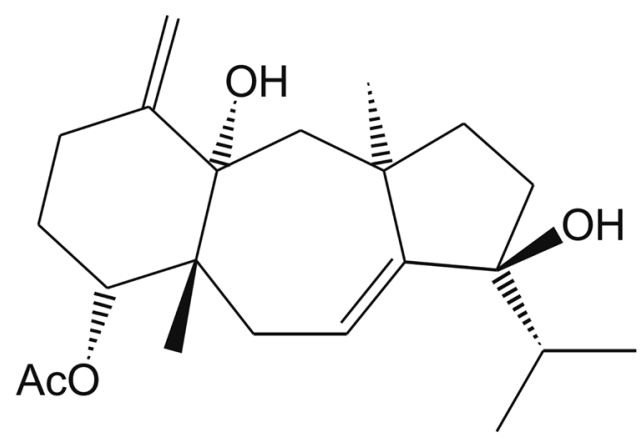

Figure 2. Effect of crude extracts (EACE, MCE and DCE), and fraction (EAF) from brown alga Canistrocarpus cervicornis against promastigote forms of Leishmania amazonensis. Each bar represents one standard deviation.

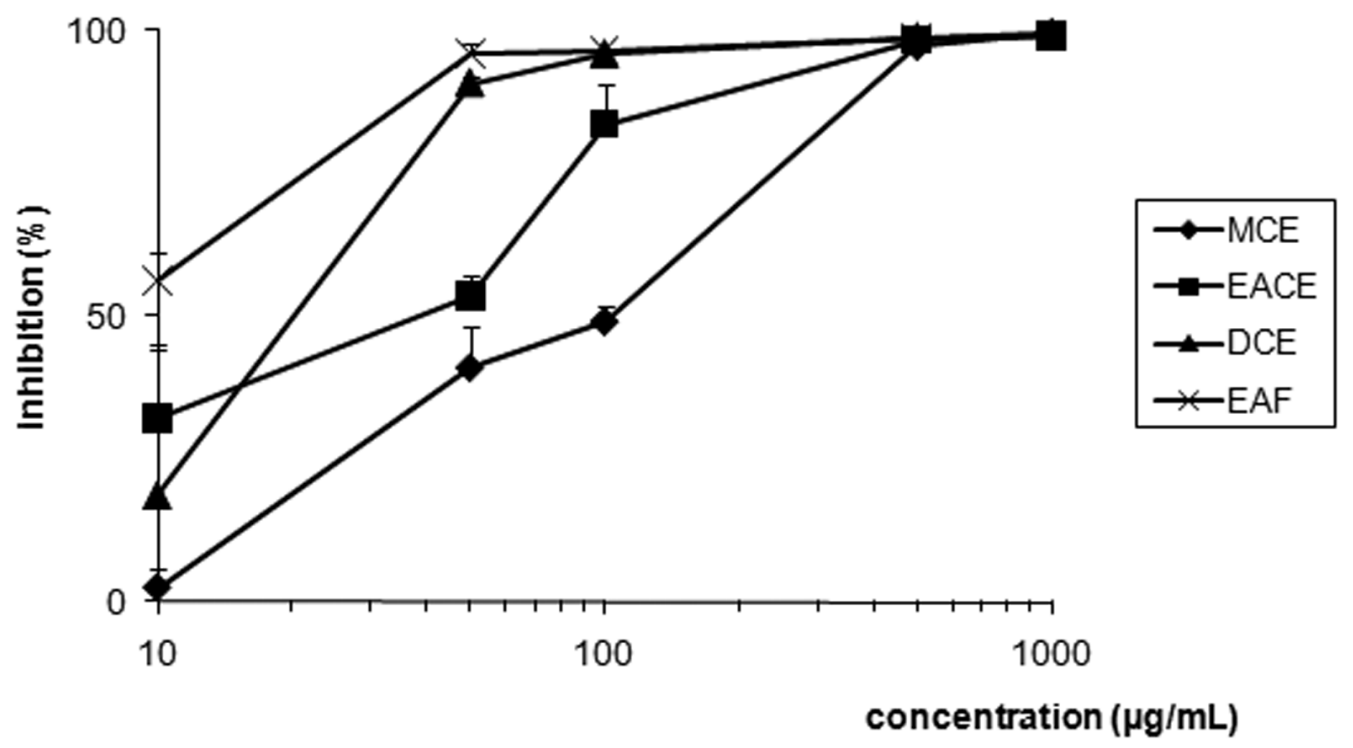


Figure 3. Effect of compound $\mathbf{1}$ from brown alga Canistrocarpus cervicornis against promastigote $(\bullet)$, and axenic amastigote $(\bullet)$ forms of Leishmania amazonensis. Each bar represents one standard deviation.

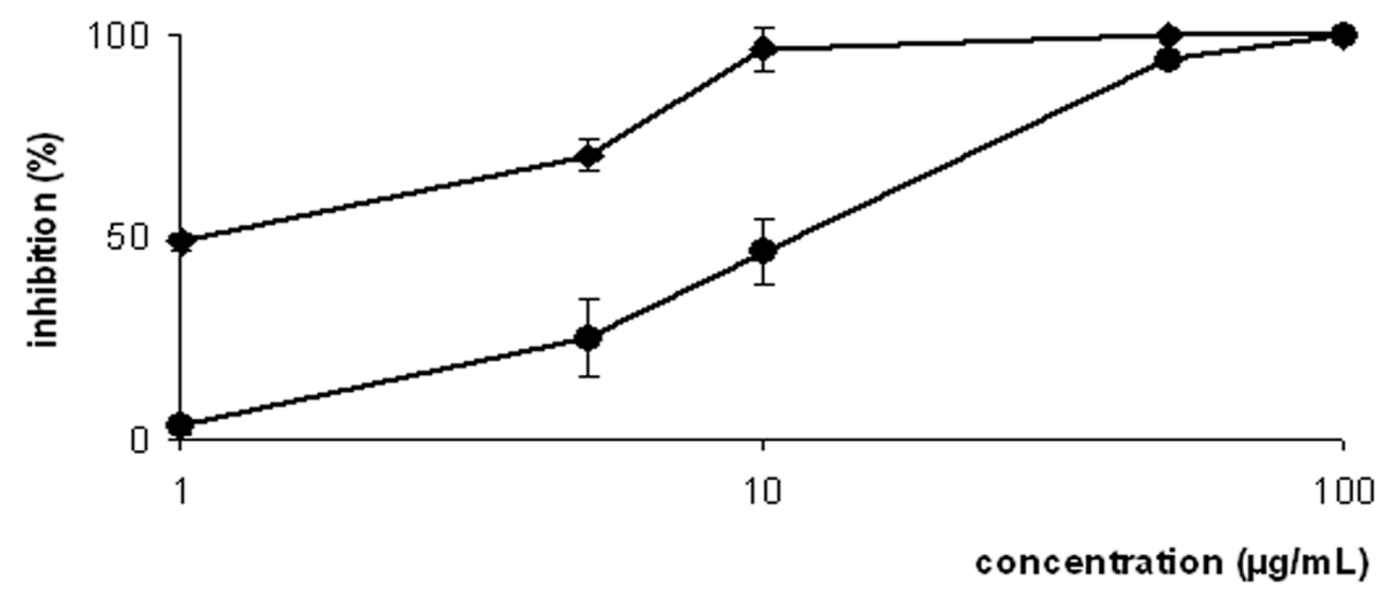

Table 1. Comparison between values of $\mathrm{CC}_{50}$ for $\mathrm{J} 774 \mathrm{G} 8$ macrophages and $\mathrm{IC}_{50}$ for promastigote forms of Leishmania amazonensis, and their respective selectivity indexes (SI).

\begin{tabular}{cccc}
\hline \multirow{2}{*}{ Compound } & \multirow{2}{*}{$\mathbf{C C}_{\mathbf{5 0}}(\boldsymbol{\mu g} / \mathbf{m L})^{\mathbf{a}}$} & \multicolumn{2}{c}{ Promastigote forms } \\
\cline { 3 - 4 } & $50.0 \pm 0.08$ & $\mathbf{I C}_{\mathbf{5 0}}(\boldsymbol{\mu} \mathbf{g} / \mathbf{m L})$ & $\mathbf{S I}$ \\
\hline EACE & $51.0 \pm 0.20$ & $50.0 \pm 2.12$ & 1.00 \\
MCE & $46.0 \pm 0.46$ & $100.0 \pm 4.50$ & 0.51 \\
DCE & $47.0 \pm 0.75$ & $20.0 \pm 1.55$ & 2.30 \\
EAF & $186.0 \pm 3.29$ & $8.0 \pm 0.55$ & 5.88 \\
$\mathbf{1}$ & nd & $2.0 \pm 0.37$ & 93.00 \\
Amphotericin-B & & $0.06 \pm 0.00$ & nd \\
\hline
\end{tabular}

Values represent the mean \pm S.D. of at least three experiments performed in triplicate. ${ }^{\text {a }}$ On macrophage strain $\mathrm{J} 774 \mathrm{G} 8$ at $48 \mathrm{~h}$ of culture. $\mathrm{SI}=\mathrm{CC}_{50} \mathrm{~J} 774 \mathrm{G} 8 / \mathrm{IC}_{50}$. nd: not determined.

The cytotoxicity on macrophage strain J774G8 of crude extracts, fraction, and isolated compound were also evaluated (Table 1). When macrophages were treated with crude extracts EACE, MCE, and DCE the $50 \%$ cytotoxic concentration $\left(\mathrm{CC}_{50}\right)$ were $50.0 \mu \mathrm{g} / \mathrm{mL}, 51.0 \mu \mathrm{g} / \mathrm{mL}$, and $46.0 \mu \mathrm{g} / \mathrm{mL}$, respectively. The $\mathrm{CC}_{50}$ of fraction (EAF) was $47.0 \mu \mathrm{g} / \mathrm{mL}$ and $\mathrm{CC}_{50}$ of 1 was $186.0 \mu \mathrm{g} / \mathrm{mL}$. The cytotoxicity to the macrophage and the activity against the protozoan were compared by using the selectivity index (SI). The better results of SI for promastigote forms were obtained with fraction EAF $(\mathrm{SI}=5.88)$ and isolated compound $1(\mathrm{SI}=93.0)$. So, EAF and 1 were respectively 5.88 and 93.0 times less toxic to the macrophage than to the protozoan.

The pure compound $\mathbf{1}$ was more active than crude extracts and fraction. Thus, further experiments were carried out using only this compound. Isolated compound $\mathbf{1}$ had the activity investigated against axenic amastigote forms of L. amazonensis (Figure 3). The $\mathrm{IC}_{50}$ obtained value was $12.0 \mu \mathrm{g} / \mathrm{mL}$. The effect of the 1 on intracellular amastigotes was observed during $24 \mathrm{~h}$ of incubation (Figure 4). Treatment of intracellular amastigotes with 5.0,15.0, and $30.0 \mu \mathrm{g} / \mathrm{mL}$ with 1 resulted in decreases in the survival index of 56.0, 72.0, and $76.0 \%$, respectively, compared to the control. Additionally, the $\mathrm{IC}_{50}$ was $4.0 \mu \mathrm{g} / \mathrm{mL}$. These results were significant at $p \leq 0.05$ as compared to the control group, by the 
student's $t$ test. In this regard, the result of this preliminary study is very encouraging because it is the amastigote forms of Leishmania that persist in the human host and directly cause all of the clinical manifestations of leishmaniasis [29]. Amphotericin B showed $\mathrm{IC}_{50}$ of 0.25 and $0.35 \mu \mathrm{g} / \mathrm{mL}$ against axenic amastigote and intracellular amastigote forms, respectively.

Figure 4. Survival index of Leishmania amazonensis within peritoneal macrophage cells treated with compound 1. (1) Untreated control; (2) Treated with 1 at $5.0 \mu \mathrm{g} / \mathrm{mL}$; (3) Treated with 1 at $15.0 \mu \mathrm{g} / \mathrm{mL}$; (4) Treated with 1 at $30.0 \mu \mathrm{g} / \mathrm{mL}$. Each bar represents the mean \pm standard error of at least three independent experiments, which were performed in duplicate. $*$ Significant difference of each group from the control $(p<0.05)$.

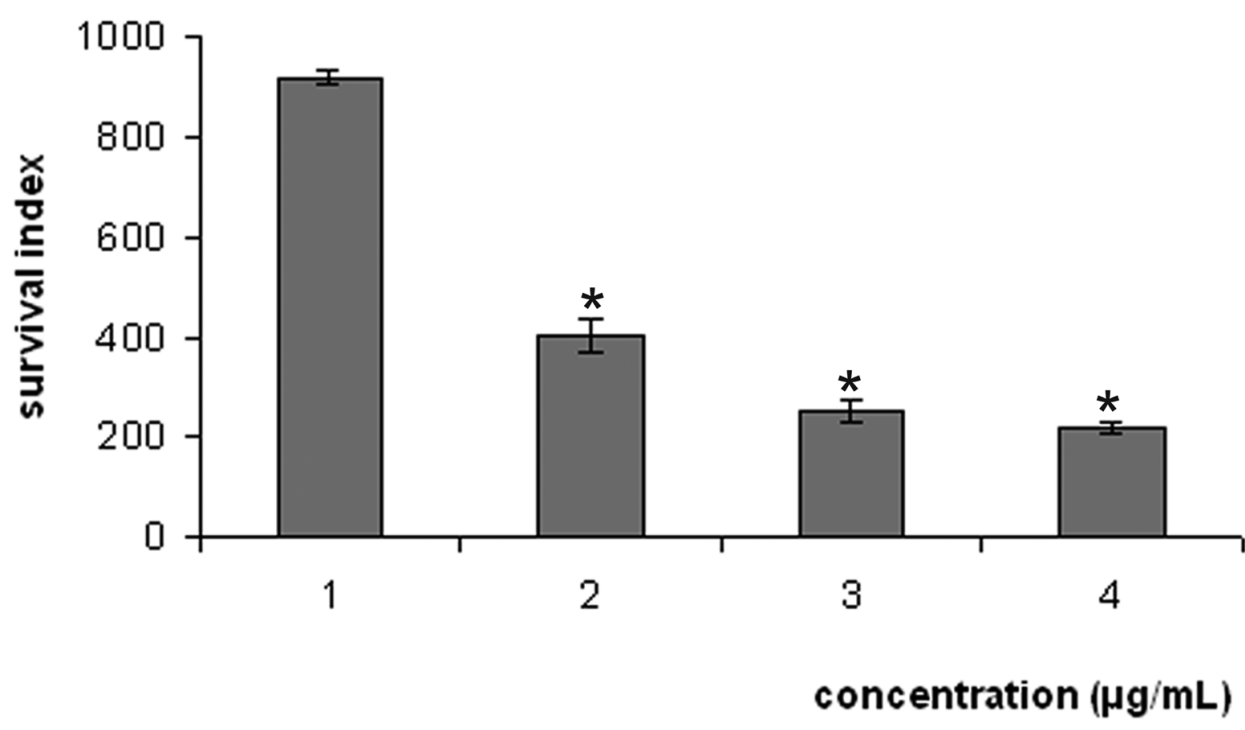

To find cellular targets in leishmania cells treated with 1, TEM and flow cytometry techniques were employed. We verified that $\mathbf{1}$ produced ultrastructural alterations in L. amazonensis. Figure 5 shows transmission electron microscopy photomicrographs of promastigotes treated with the isolated compound 1. Figure 5A shows untreated cells with a terminal flagellum, nucleus, and the single mitochondrion with a branched structure, characteristic of this group of organisms, containing a disk-shaped aggregate of DNA called a kinetoplast. In L. amazonensis treated with 1, we highlight that the main alteration which occurred in the mitochondria of the parasite, was seen as intense mitochondrial swelling, as seen in Figure 5B-F.

In accordance with these findings, tests using specific markers for mitochondria were performed. Data obtained from a flow cytometry by using Rh123 presented in Figure 6 showed a marked decrease in the percentage population of upper right gate $(76.55 \%$ and $68.71 \%)$. This indicates depolarization of the mitochondrial membrane potential in the cells following treatment with $\mathbf{1}$ at $50 \mu \mathrm{g} / \mathrm{mL}$ and $100 \mu \mathrm{g} / \mathrm{mL}$, respectively (Figure 6). Similarly, a decrease in membrane potentials was also observed following treatment with the standard drug Carbonyl Cyanide $m$-chlorophenylhydrazone (CCCP) (75.37\%) at $200 \mu \mathrm{M}$ for $3 \mathrm{~h}$ at $32{ }^{\circ} \mathrm{C}$. In contrast, untreated cells maintained the membrane potential (98.41\%) (Figure 6, upper right quadrant). The student's $t$ test $(p<0.05)$ indicated significant differences between cells treated with copaiba oil compared to the negative control group. 
Figure 5. Ultrastructural effect of compound 1 after incubation for $72 \mathrm{~h}$ at $25{ }^{\circ} \mathrm{C}$ on promastigotes forms of Leishmania amazonensis observed by Transmission Electron Microscopy. (A) Promastigote Control; (B and C) Promastigote forms treated with $2 \mu \mathrm{g} / \mathrm{mL}$ of $\mathbf{1}$; (D to F) Promastigote forms treated with $10 \mu \mathrm{g} / \mathrm{mL}$ of $\mathbf{1}$. The treatment led to notable swollen mitochondrial (black stars). n, nucleus; f, flagellum; fp, flagellar pocket; $\mathrm{k}$, kinetoplast; $\mathrm{m}$, mitochondrion. Bars $=1 \mu \mathrm{m}$.

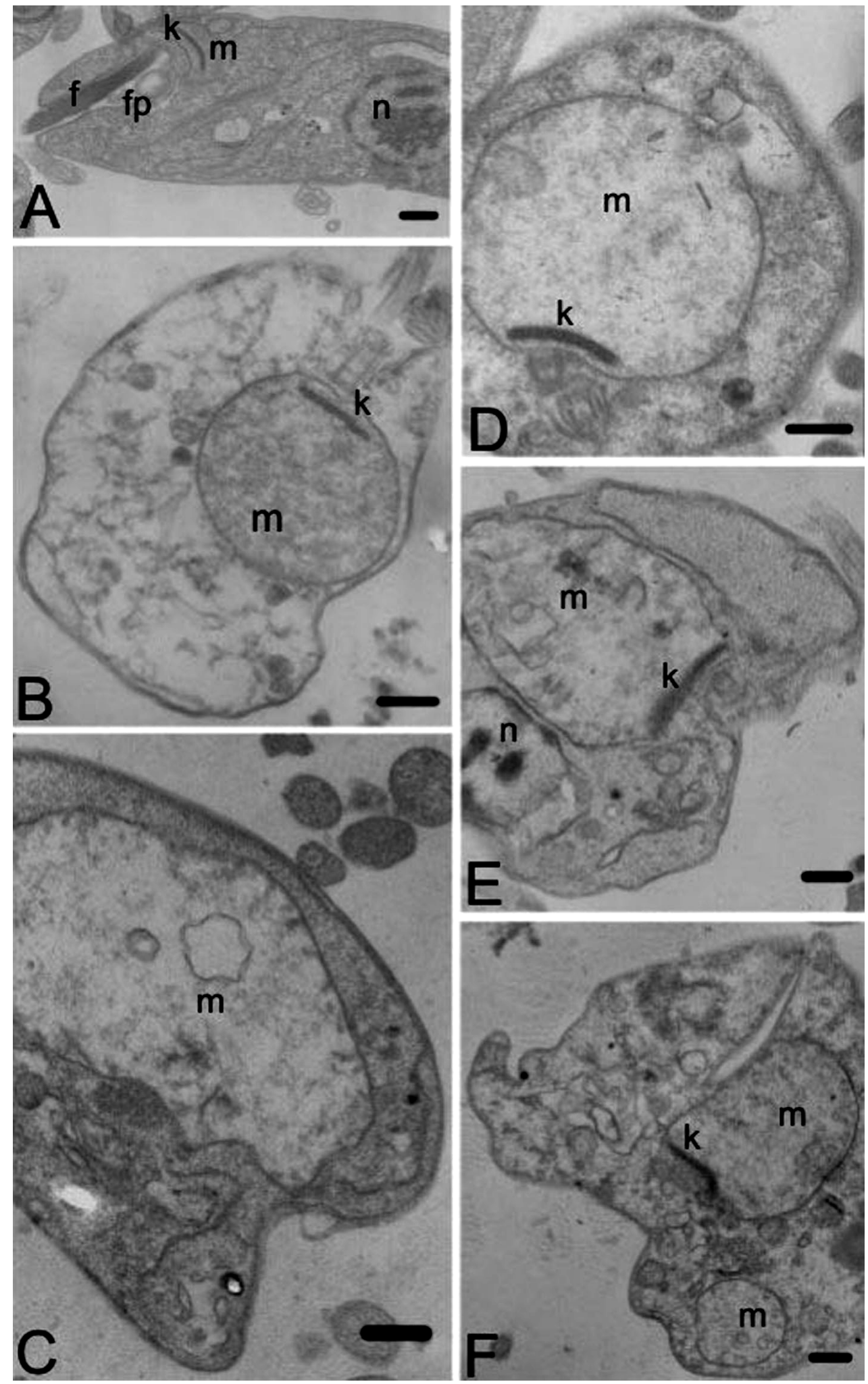


Figure 6. Flow cytometry analysis of Rh123-labeled axenic amastigotes of Leishmania amazonensis. Compound 1 collapsed the $\Delta \Psi \mathrm{m}$, leading to parasite death. (A) Untreated cells; (B) CCCP $200 \mu \mathrm{M}$; (C) Amastigotes treated with $50 \mu \mathrm{g} / \mathrm{mL}$; (D) Amastigotes treated with $100 \mu \mathrm{g} / \mathrm{mL}$. The bold numbers represent the percentage of the collapsed $\Delta \Psi \mathrm{m}$ cells in the upper right quadrant.
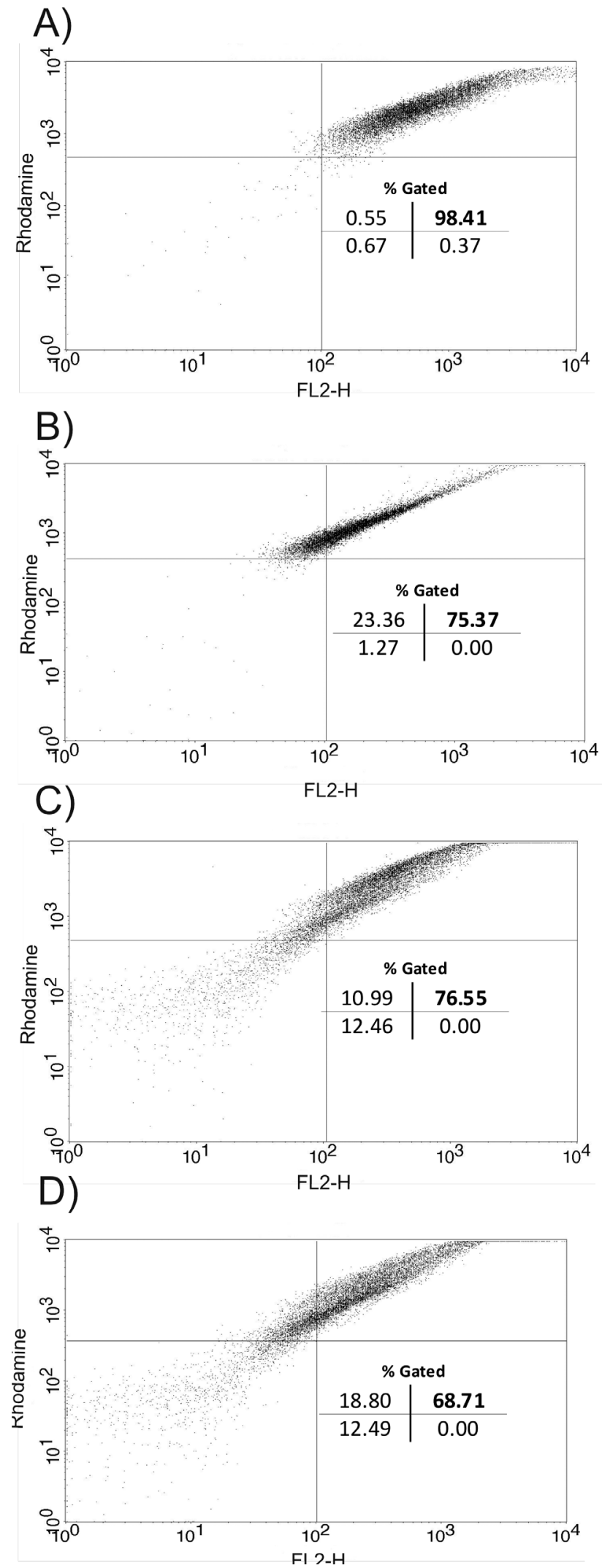
Mitochondrion found in trypanosomatid parasites had distinct structural and functional characteristics of mammalian cells making this organelle an exceptionally attractive chemotherapeutic target. Likewise, investigations have shown that mitochondria can be targeted by different drugs for Leishmania sp. [13,14,30-32]. Additionally, several studies have reported that mitochondrial alterations may lead to programmed cell death by apoptosis [33-36].

In order to evaluate the effects of the compound 1, the lipid peroxidation of cell membrane was determined. It was assessed by measuring TBARS in leishmanial cells after treatment with $\mathbf{1}$ compared to control or untreated cells (Figure 7). In addition, thenoyltrifluoroacetone (TTFA), a conventional mitochondrial complex II inhibitor, was used as positive control. Compound 1 treatment at $100 \mu \mathrm{g} / \mathrm{mL}$ displayed an increase in lipid peroxides after $6 \mathrm{~h}$ of drug treatment, with a 3.4-fold lipoperoxidation compared to the untreated control cells while the increase in lipid peroxidation obtained with the TTFA was 2.1-fold compared to the control. Previous studies have demonstrated that loss of the mitochondrial membrane potentially induces formation of reactive oxygen species (ROS) inside cells, which induces lipid peroxidation. Moreover, the cellular ROS generation in turn leads to the damage of the oxidative citoplasmatic membrane, and DNA lesions [33,34,37,38].

Figure 7. Effect of compound 1 on lipid peroxidation (production of malondialdehyde (MDA)) of amastigote forms of Leishmania amazonensis. Each bar represents the mean \pm standard error of at least three independent experiments, which were performed in duplicate. * Significant difference of each group from the control $(p<0.05)$.

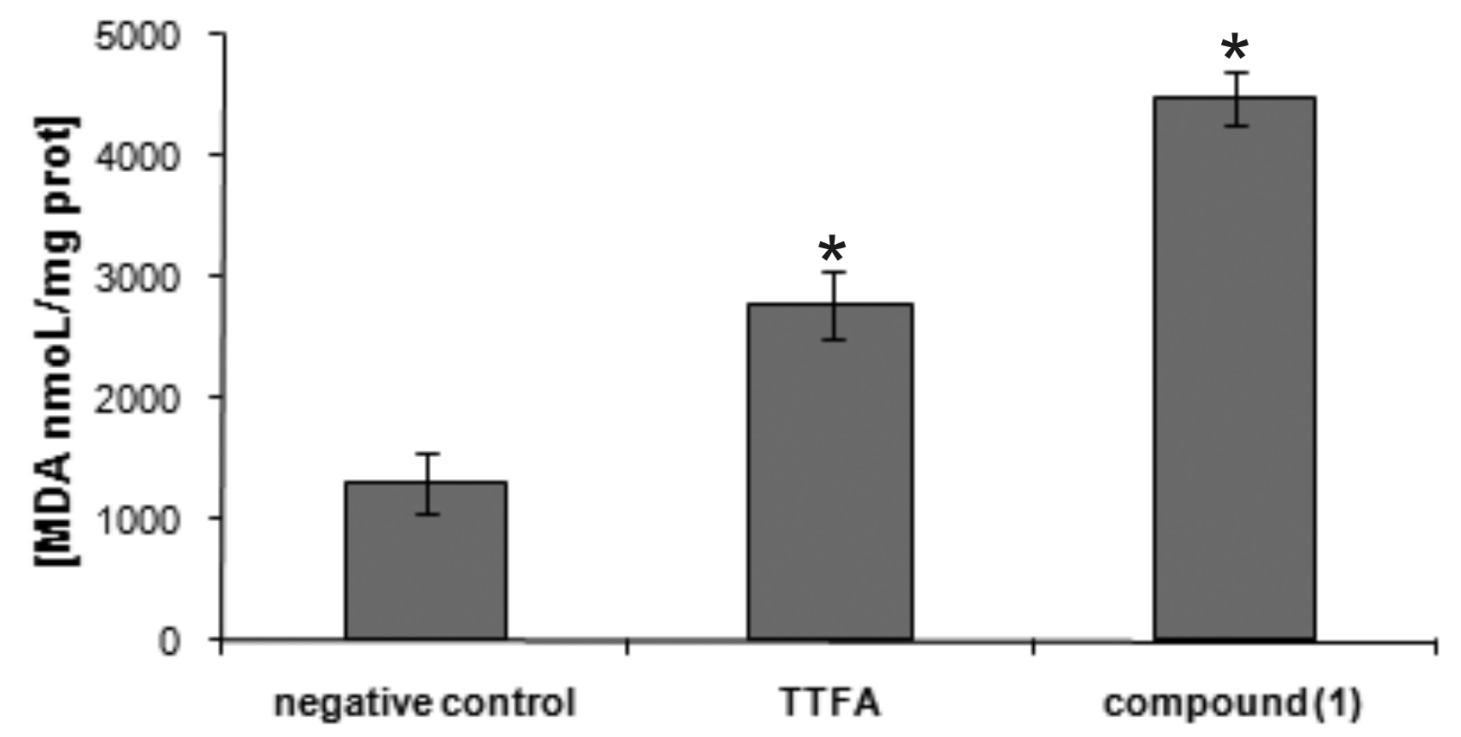

\section{Experimental Section}

\subsection{Algal Collection}

Specimens of the brown macroalga C. cervicornis (Dictyotaceae, Phaeophyta) were collected by free diving off the coast of Paraíso Beach, Pernambuco State, Brazil $\left(08^{\circ} 21^{\prime} \mathrm{S}, 34^{\circ} 57^{\prime} \mathrm{W}\right)$, in October 2009, at depths between 1 and $2 \mathrm{~m}$. The algal material was cleaned manually from epiphytic organisms and air-dried immediately after collection. Voucher specimens were deposited in the Herbarium of Universidade Federal de Pernambuco, Recife, Brazil (62948). 


\subsection{Chemical Extraction}

The air-dried algal material (300.0 g of C. cervicornis) was extracted in dichloromethane $\left(\mathrm{CH}_{2} \mathrm{Cl}_{2}\right)$ at room temperature for 30 days and the solvent was evaporated in vacuo by rota-evaporation, yielding $14.6 \mathrm{~g}$ of dry dichloromethane crude extract (DCE). The residue was further extracted in ethyl acetate (EtOAc) using similar procedures, yielding $0.9 \mathrm{~g}$ of dry ethyl acetate crude extract (EACE), and finally extracted in methanol $(\mathrm{MeOH})$, yielding $0.3 \mathrm{~g}$ of dry methanol crude extract (MCE).

\subsection{Fractionation and Compound Isolation}

A part of DCE (5 g) was subjected to silica gel 70-230 mesh column chromatography $(3.5 \times 25 \mathrm{~cm})$, eluted with $n$-hexane, $\mathrm{CH}_{2} \mathrm{Cl}_{2}$, EtOAc, $\mathrm{Me}_{2} \mathrm{CO}$, and $\mathrm{MeOH}$ in sequence, to give 45 fractions of $20 \mathrm{~mL}$ each one (F1-F45). The fractions F12-F25 eluted with $\mathrm{CH}_{2} \mathrm{Cl}_{2}$ showed similar when analyzed by TLC and it were combined to produce a dark brown-green residue $(1.2 \mathrm{~g})$, which was subjected to new silica gel 70-230 mesh column chromatography $(2 \times 25 \mathrm{~cm})$ eluted with $n$-hexane/EtOAc $(3: 1)$ increasing the polarity until 100\% AcOEt, to give 48 fractions (F1-F48, $10 \mathrm{~mL}$ each one). The fractions F14-F18 were analyzed by TLC and showed intense browns spots $(\mathrm{Rf}=0.47$, mobile phase $n$-hexane/EtOAc $3: 1)$, then it was combined $(200 \mathrm{mg})$. Following this, fractions were subjected to new silica gel 70-230 mesh column chromatography $(1.0 \times 20 \mathrm{~cm})$, eluted with $n$-hexane/EtOAc (4:1), to give 20 fractions (F1-F20). The Fraction F8 afforded the pure compound $(4 R, 9 S, 14 S)-4 \alpha$-acetoxy-9 $\beta, 14 \alpha$-dihydroxydolast-1(15), 7-diene (1) (143.0 mg, yellow gum).

The fractions F26-F38 eluted with EtOAc from DCE showed similar results when analyzed by TLC, and then they were combined to produce a brownish residue $(1.3 \mathrm{~g})$ which was named EAF (ethyl acetate fraction).

All the crude extracts formed (EACE, DCE, and MCE), fraction (EAF) and pure compound isolated 1 were monitored by TLC using silica gel $\mathrm{GF}_{254}$ (Merck) as stationary phase and $n$-hexane/EtOAc 3:1 and $4: 1$ as mobile phase. The chromatoplates used were revealed through spraying it with a solution of ceric sulphate and sulfuric acid acquired by $2.1 \mathrm{~g}$ of $\mathrm{Ce}_{2}\left(\mathrm{SO}_{4}\right)_{3} \cdot 4 \mathrm{H}_{2} \mathrm{O} ; 21 \mathrm{~mL}$ of $\mathrm{H}_{2} \mathrm{SO}_{4}$ and $300 \mathrm{~mL}$ of $\mathrm{H}_{2} \mathrm{O}$, followed by heating at $100{ }^{\circ} \mathrm{C}$ for $3 \mathrm{~min}$.

\subsection{Spectroscopic Data}

The physical and spectroscopic properties of the diterpene $(4 R, 9 S, 14 S)-4 \alpha$-acetoxy- $9 \beta, 14 \alpha$-dihydro xydolast-1(15),7-diene (143.0 mg, yellowish gum) were found to be identical with the previously reported data [39].

\subsection{Parasites}

Leishmania promastigotes were grown in Warren's medium (brain-heart infusion plus hemin and folic acid) $\mathrm{pH} 7.2$, supplemented with 10\% heat-inactivated fetal bovine serum (FBS; Gibco Invitrogen Corporation, New York, USA), at $24{ }^{\circ} \mathrm{C}$ in a tissue flack. The strain used was Leishmania amazonensis (MHOM/BR/Josefa) originally isolated from a human case of difuse cutaneous leishmaniasis. 
Leishmania axenic amastigotes were obtained by in vitro transformation of infective promastigotes [40]. These forms were maintained in Schneider's medium (Sigma, St. Louis, MO, USA) $\mathrm{pH} 4.6$, supplemented with $20 \%$ heat-inactivated FBS, at $32{ }^{\circ} \mathrm{C}$ in a tissue flask.

\subsection{Macrophage J774G8 Cells}

Murine macrophage J774G8 cells were maintained in tissue flasks composed of RPMI 1640 medium (Gibco Invitrogen Corporation, New York, USA), sodium bicarbonate, L-glutamine, and supplemented with $10 \%$ heat-inactivated FBS in a $5 \% \mathrm{CO}_{2}$-air-mixture.

\subsection{Antileishmania Activity in Vitro against Promastigotes and Axenic Amastigotes}

The growth inhibition test that was performed on promastigotes forms of L. amazonensis from a $48 \mathrm{~h}$ logarithmic phase culture was suspended to yield $1 \times 10^{6}$ parasites $/ \mathrm{mL}$. It was then cultivated in 24-well culture plates at $25{ }^{\circ} \mathrm{C}$ in Warren's medium, supplemented with $10 \%$ FBS in the presence or absence of increasing concentration of 1 for $72 \mathrm{~h}$. In a same way, axenic amastigotes forms of L. amazonensis from 72-h-old logarithmic-phase culture were suspended to yield $1 \times 10^{6}$ parasites $/ \mathrm{mL}$, and then were cultivated in 12-well culture plates at $32{ }^{\circ} \mathrm{C}$ in Schneider's medium. Next they were supplemented with $20 \%$ FBS in the presence or absence of increasing concentration of compound 1 for $72 \mathrm{~h}$. Amphotericin was used as a positive control. DMSO was used for the solubilized drugs, but the final DMSO concentration did not exceed $0.5 \%$, which did not show deleterious effects on the parasites. The leishmanicidal activity was determined by direct counting of the cells in a Neubauer chamber and the $50 \%$ inhibition concentration $\left(\mathrm{IC}_{50}\right)$ was obtained graphically by plotting concentration versus percentage of growth inhibition.

\subsection{Activity against Intracellular Amastigotes}

For assay of the effects of the compound on intracellular amastigotes, peritoneal macrophages of $\mathrm{BALB} / \mathrm{C}$, mice were used. Peritoneal macrophages $\left(5 \times 10^{5}\right.$ cells $\left./ \mathrm{mL}\right)$ were plated on coverslips (diameter $13 \mathrm{~mm}$ ) in 24 well plate in RPMI 1640 medium supplemented with $10 \%$ inactive FBS, and incubated for $24 \mathrm{~h}$ at $37{ }^{\circ} \mathrm{C}$ in a $5 \% \mathrm{CO}_{2}$ atmosphere for adherence, after the peritoneal macrophages were infected with promastigotes of L. amazonensis in multiples of 10 parasites per host cell and incubated at $37{ }^{\circ} \mathrm{C}$ in a $5 \% \mathrm{CO}_{2}$ atmosphere. After $6 \mathrm{~h}$ of infection, infected macrophages were treated with compound in concentrations 10, 20 and $30 \mu \mathrm{g} / \mathrm{mL}$ and incubated $24 \mathrm{~h}$ again. Afterwards the monolayer's were washed with PBS, fixed with methanol, and stained with Giemsa. The percentage of infected macrophages and the mean numbers of amastigotes/infected macrophage were determined by counting at least 200 macrophages in duplicate cultures, and results were expressed as shown in the survival index. The survival index was obtained by multiplying the percentage of macrophages cells with parasites by the mean number of internalized parasites per cell.

\subsection{Cytotoxicity Assay}

The cytotoxicity assay was performed in 96-well plates. A suspension of $5 \times 10^{5} \mathrm{~J} 774 \mathrm{G} 8$ cells in RPMI 1640 medium supplemented with 10\% FBS was added to each well in 96-well microtiter plates. 
The plates were incubated in a $5 \% \mathrm{CO}_{2}$-air mixture at $37^{\circ} \mathrm{C}$ to obtain confluent growth of the cells. After $24 \mathrm{~h}$, the medium was removed and the cells were treated with several concentrations of compounds and the plates were incubated for $48 \mathrm{~h}$. Control cells without compound were included. The adhered macrophages were fixed with $50 \mu \mathrm{L} /$ well of $10 \%$ trichloroacetic acid at $4{ }^{\circ} \mathrm{C}$ for $1 \mathrm{~h}$; after that, the well plates were washed with water, and attained with $50 \mu \mathrm{L} /$ well of sulforhodamine $\mathrm{B}$ $(0.4 \% \mathrm{w} / \mathrm{v})$ in $1 \%$ acetic acid solution; the microplate was then maintained at $4{ }^{\circ} \mathrm{C}$ for $30 \mathrm{~min}$. Next, the microplate was washed five times with $1 \%$ acetic acid to remove the sulforhodamine $\mathrm{B}$, then $150 \mu \mathrm{L} /$ well of $10 \mathrm{mM}$ unbuffered Tris-base solution (Sigma) was added. The absorbance of each individual well was read at $530 \mathrm{~nm}$. Dose-response curves were plotted (values expressed as percentage of control optical density) and the $50 \%$ cytotoxicity concentration $\left(\mathrm{CC}_{50}\right)$ was determined by logarithm regression analysis of the data obtained.

\subsection{Transmission Electron Microscopy}

Ultrastructural analysis was performed on promastigote forms of L. amazonensis treated with 2.0 and $10.0 \mu \mathrm{g} / \mathrm{mL}$ of the compound $\mathbf{1}$, after $48 \mathrm{~h}$ for treatment, the parasites were washed in $0.1 \mathrm{M}$ phosphate-buffered saline and fixed in $2.5 \%$ glutaraldehyde in $0.1 \mathrm{M}$ sodium cacodylate buffer at $4{ }^{\circ} \mathrm{C}$. The cells were post fixed in a solution containing $1 \%$ osmium tetroxide, $0.8 \%$ potassium ferrocyanide, and $5 \mathrm{mM}$ calcium chloride in $0.1 \mathrm{M}$ cacodylate buffer. Next they were washed in the same buffer, dehydrated in increasing concentrations of acetone and embedded in Epon resin. Ultrathin sections obtained in an ultramicrotome were stained with uranyl acetate and lead citrate and examined in a Zeiss 900 transmission electron microscope.

\subsection{Flow Cytometry}

The L. amazonensis axenic amastigotes $\left(5 \times 10^{6}\right.$ parasites $\left./ \mathrm{mL}\right)$ were treated with 1 (50, and $100 \mu \mathrm{g} / \mathrm{mL}$ for $3 \mathrm{~h}$ at $32{ }^{\circ} \mathrm{C}$ ), or untreated were harvested and washed with PBS. To gain analyses of mitochondrial membrane potential, $(\Delta \Psi \mathrm{m})$ parasites were stained with Rhodamine 123 (Rh 123) $\left(5 \mathrm{mg} / \mathrm{mL}\right.$ for $30 \mathrm{~min}$ at $37{ }^{\circ} \mathrm{C}$ ) reagent following the protocol of manufacturer. The mean of fluorescence intensity of the cells was analyzed by flow cytometry FACSCalibur and CellQuest software). A total of 10,000 events were acquired in the region previously established as that corresponding to the parasites.

\subsection{Measurement of Lipid Peroxidation Product}

Samples of axenic amastigotes in exponential phase, were treated with $100 \mu \mathrm{g} / \mathrm{mL}$ of compound 1 for $6 \mathrm{~h}$, at $32{ }^{\circ} \mathrm{C}$. The thenoyltrifluoroacetone (TTFA) was used as positive control. After treatment, cells were washed with phosphate buffer, homogenized and added to a solution of $0.37 \%$ thiobarbituric acid in $15 \%$ trichloroacetic acid and $0.25 \mathrm{~N} \mathrm{HCl}$. The mixture was heated at $90-95{ }^{\circ} \mathrm{C}$ for $45 \mathrm{~min}$. After cooling, butanol (1:1) was added to the solution. The mixture was shaken and centrifuged at $2000 \times g$ during $5 \mathrm{~min}$. The optical density of the organic layer was determined at $535 \mathrm{~nm}$ in BIO-TEK Power Wave XS spectrophotometer. Lipid peroxidation was determined by the generation of 
thiobarbituric acid-reactive substances (TBARS) in terms of malondialdehyde (MDA), expressed in MDA nmol $\times$ protein $\mathrm{mg}^{-1}[41]$.

\subsection{Statistical Analysis}

All experiments were performed in duplicate. The means and standard deviations were determined from at least three experiments. Statistical analysis was performed with the program GraphPad Prism 4 (GraphPad Software, San Diego, California, USA). The student's $t$ test was applied, and a $p$ value less than 0.05 were regarded as significant.

\section{Conclusions}

New antileishmanials from natural products are urgently needed due to the emergence of drug resistance in patients. In this context, the use of the compound $\mathbf{1}$ isolated from C. cervicornis against $L$. amazonensis parasites is of great interest. The in vitro treatment of the parasites with compound 1 showed notable ultra structural changes, displayed depolarization in the mitochondrial membrane potential, and an increase of lipid peroxidation. Although the mechanism of action of the compound $\mathbf{1}$ is still unclear, these findings appear to be a future alternative to development of new antileishmanial drugs.

\section{Acknowledgments}

E. M. B. thanks the Coordenação de Aperfeiçoamento de Pessoal de Nível Superior (CAPES) for providing his post doc fellowship (PRODOC 2009-2010) and the Daniela Maria do Amaral Ferraz Navarro (DQF/UFPE) for laboratory support. The authors are grateful to Fabíola Barbieri Holetz (FIOCRUZ/PE) for help in the algae collection, Ricardo Oliveira da Silva (DQF/UFPE) for acquisition of NMR spectra marine compounds, and M.Sc. Thiago Nogueira de Vasconcelos Reis (DO/UFPE) for identification of algal material.

This study was supported through grants from the Conselho Nacional de Desenvolvimento Científico e Tecnológico - CNPq, Capacitação de Aperfeiçoamento de Pessoal de Nível Superior-CAPES, Financiadora de Estudos e Projetos_FINEP, PRONEX/Fundação Araucária.

\section{References}

1. World Health Organization. Leishmaniasis: Disease Burden and Epidemiological Trends; WHO: Geneva, Switzerland, 2009. Avaiable online: http:/www.who.int/tdr/diseases/leish/files/ direction.pdf (accessed on 30 July 2011).

2. Mitropoulos, P.; Konidas, P.; Durkin-Konidas, M. New World cutaneous leishmaniasis: Updated review of current and future diagnosis and treatment. J. Am. Acad. Dermatol. 2010, 6, 309-322.

3. Zucca, M.; Savoia, D. Current developments in the therapy of protozoan infections. Open Med. Chem. J. 2011, 5, 4-10.

4. Reithinger, R.; Dujardin, J.C.; Louzir, H.; Pirmez, C.; Alexander, B.; Broker, S. Cutaneous leishmaniasis. Lancet Infect. Dis. 2007, 7, 581-596.

5. Chawla, B.; Madhubala, R. Drug targets in Leishmania. J. Parasit. Dis. 2010, 34, 1-13. 
6. Tiuman, T.S.; Santos, A.O.; Ueda-Nakamura, T.; Dias-Filho, B.P.; Nakamura, C.V. Recent advances in leishmaniasis treatment. Int. J. Infect. Dis. 2011, doi:10.1016/j.ijid.2011.03.021.

7. Mayer, A.M.S.; Glaser, K.B.; Cuevas, C. The odyssey of marine pharmaceuticals: A current pipeline perspective. Trends Pharm. Sci. 2010, 31, 255-265.

8. Pereira, R.C.; Bianco, E.M.; Bueno, L.B.; Oliveira, M.A.L.; Pamplona, O.S.; Da-Gama, B.A.P. Associational defense against herbivory between brown seaweeds. Phycologia 2010, 49, 424-428.

9. Barbosa, J.P.; Fleury, B.G.; Da-Gama, B.A.P.; Teixeira, V.L.; Pereira, R.C. Natural products as antifoulants in the Brazilian brown alga Dictyota pfaffii (Phaeophyta, Dictyotales). Biochem. Syst. Ecol. 2007, 35, 549-553.

10. Bianco, E.M.; Rogers, R.; Teixeira, V.L.; Pereira, R.C. Antifoulant diterpenes produced by the brown seaweed Canistrocarpus cervicornis. J. Appl. Phycol. 2009a, 21, 341-346.

11. Engel, S.; Jensen, P.R.; Fenical, W. Chemical ecology of marine microbial defense. J. Chem. Ecol. 2002, 28, 1971-1985.

12. Barbosa, J.P.; Pereira, R.C.; Abrantes, J.L. Cirne dos Santos, C.C.; Rabello, M.A.; Frugulhetti, I.C.; Teixeira, V.L. In vitro antiviral diterpenes from the Brazilian brown alga Dictyota pfaffii. Planta Med. 2004, 70, 856-860.

13. Veiga-Santos, P.; Rocha, K.J.P.; Santos, A.O.; Ueda-Nakamura, T.; Dias-Filho, B.P.; Silva, S.O.; Sudatti, D.B.; Bianco, E.M.; Pereira, R.C.; Nakamura, C.V. In vitro anti-trypanosomal activity of elatol isolated from red seaweed Laurencia dendroidea. Parasitology 2010, 137, 1661-1670.

14. Santos, A.O.; Veiga-Santos, P.; Ueda-Nakamura, T.; Dias-Filho, B.P.; Sudatti, D.B.; Bianco, E.M.; Pereira, R.C.; Nakamura, C.V. Effect of elatol, isolated from red seaweed Laurencia dendroidea, on Leishmania amazonensis. Mar. Drugs 2010, 29, 2733-2743.

15. Morales, J.L.; Cantillo-Ciau, Z.O.; Sánchez-Molina, I.; Mena-Rejón, G.J. Screening of antibacterial and antifungal activities of six marine macroalgae from coasts of Yucatán Península. Pharm. Biol. 2006, 44, 632-635.

16. Zubia, M.; Robledo, D.; Freile-Pelegrin, Y. Antioxidant activities in tropical marine macroalgae from the Yucatan Peninsula, México. J. Appl. Phycol. 2007, 19, 449-458.

17. Medeiros, V.P.; Queiroz, K.C.S.; Cardoso, M.L.; Monteiro, G.R.; Oliveira, F.W.; Chavante, S.F.; Guimaraes, L.A.; Rocha, H.A.; Leite, E.L. Sulfated galactofucan from Lobophora variegata: Anticoagulant and anti-inflammatory properties. Biochemistry 2008, 73, 1018-1024.

18. Teixeira, V.L.; Tomassini, T. Dolastane and secodolastane diterpenes from the marine brown alga Dictyota cervicornis. J. Nat. Prod. 1986, 49, 570-575.

19. Bianco, E.M.; Teixeira, V.L.; Pereira, R.C.; De-Souza, A.M.; Nucci, P.; Afonso, I.F.; Rodrigues, C.R.; Castro, H.C. Brown seaweed defensive chemicals: A structure-activity relationship approach for the marine environment. Nat. Prod. Commun. 2009b, 4, 173-178.

20. Moura, L.A.; Sanchez, E.F.; Bianco, E.M.; Pereira, R.C.; Teixeira, V.L.; Fuly, A.L. Antiophidian properties of a dolastane diterpene isolated from the marine brown alga Canistrocarpus cervicornis. Biol. Med. Prev. Nutr. 2011, 1, 61-66.

21. Moura, L.A.; Bianco, E.M.; Pereira, R.C.; Teixeira, V.L.; Fuly, A.L. Anticoagulation and antiplatelet effects of a dolastane diterpene isolated from the marine brown alga Canistrocarpus. J. Thromb. Thrombolysis 2011, 31, 235-240. 
22. Pereira, R.C.; Pinheiro, M.D.; Teixeira, V.L.; Da-Gama, B.A.P. Feeding preferences of the endemic gastropod Astraea latispina in relation to chemical defenses of brazilian tropical seaweeds. Braz. J. Biol. 2002, 62, 33-40.

23. Vallim, M.A.; Barbosa, J.E.; Cavalcanti, D.N.; De-Paula, J.C.; Silva, V.A.G.G.; Teixeira, V.L.; Paixão, I.C.N.P. In vitro antiviral activity of diterpenes isolated from the Brazilian brown alga Canistrocarpus cervicornis. J. Med. Plant Res. 2010, 4, 2379-2382.

24. Calvalcanti, D.N.; Rezende, C.M.; Pinto, A.C.; Pereira, R.C.; Teixeira, V.L. Diterpenoid constituents from the brown alga Dictyota menstrualis (Dictyotaceae, Phaeophyta). Nat. Prod. Commun. 2006, 8, 609-611.

25. Freitas, O.S.P.; Oliveira, A.S.; Paula, J.C.; Pereira, R.C.; Cavalcanti, D.N.; Teixeira, V.L. Chemical variation in the diterpenes from the Brazilian Brown Alga Dictyota mertensii (Dictyotaceae, Phaeophyta). Nat. Prod. Commun. 2007, 2, 13-15.

26. Bianco, E.M.; Teixeira, V.L.; Pereira, R.C. Chemical defenses of the tropical marine seaweed Canistrocarpus cervicornis against herbivory by sea urchin. Braz. J. Ocean 2010, 58, 213-218.

27. Demunshi, Y.; Chugh, A. Role of traditional knowledge in marine bioprospecting. Biodivers. Conserv. 2010, 19, 3015-3033.

28. Blunt, J.W.; Copp, B.R.; Munro, M.H.G.; Northcote, P.T.; Prinsep, M.R. Marine natural products. Nat. Prod. Rep. 2011, 28, 196-268.

29. Kima, P.E. The amastigote forms of Leishmania are experts at exploiting host cell processes to establish infection and persist. Int. J. Parasitol. 2007, 37, 1087-1096.

30. Rodrigues, J.C.F.; Bernardes, C.F.; Visbal, G.; Urbina, J.A.; Vercesi, A.E.; Souza, W. Sterol methenyl tranferase inhibitors alter the ultrastructure and function of the Leishmania amazonensis mitochondrion leading to potent growth inhibition. Protist 2007, 158, 447-456.

31. Ghosh, S.; Debnath, S.; Hazra, S.; Hazra, S.; Hartung, A.; Thomale, K.; Schulthesis, M.; Kapkova, P.; Schurigt, U.; Moll, H.; et al. Valeriana wallichii root extracts and fractions with activity against Leishmania spp. Parasitol. Res. 2010, 108, 861-871.

32. Santos, A.O.; Ueda-Nakamura, T.; Dias-Filho, B.P.; Veiga-Junior, V.F.; Nakamura, C.V. Copaiba oil: An alternative to development of new drugs against Leishmaniais. Evid. Based Complement. Alternat. Med. 2012, 2012, doi:10.1155/2012/898419.

33. Santa-Rita, R.M.; Barbosa, H.S.; de Castro, S.L. Ultrastructural analysis of edelfosine-treated trypomastigotes and amastigotes of Trypanosoma cruzi. Parasitol. Res. 2006, 100, 187-190.

34. Sen, R.; Bandyopadhyay, S.; Dutta, A.; Mandal, G.; Gangyly, S.; Saha, P.; Chatterjee, M. Artemisinin triggers induction of cell-cycle arrest and apoptosis in Leishmania donovani promastigotes. J. Med. Microbiol. 2007, 56, 1213-1218.

35. Roy, A.; Ganguly, A.; BoseDasgupta, S.; Das, B.B.; Pal, C.; Jaisanka, P.; Majumder, H.K. Mitochondria-dependent reactive oxygen species-mediated programmed cell death induced by 3,3'-diindolylmethane through inhibition of F0F1-ATP synthase in unicellular protozoan parasite Leishmania donovani. Mol. Pharmacol. 2008, 74, 1292-1307.

36. Kaur, J.; Singh, N.; Singh, B.K.; Dube, A.; Tripathi, R.P.; Singh, P.; Singh, N. Leishmania donovani: Oral therapy with glycosyl 1,4-dihydropyridine analogue showing apoptosis like phenotypes targeting pteridine reductase 1 in intracellular amastigotes. Exp. Parasitol. 2010, 125, 310-314. 
37. Sen, N.; Das, B.B.; Ganguly, A.; Mukherjee, T.; Tripathi, G.; Bandyopadhyay, S.; Rakshit, S.; Sen, T.; Majumder, H.K. Camptothecin induced mitochondrial dysfunction leading to programmed cell death in unicellular hemoflagellate Leishmania donovani. Cell Death Differ. 2004, 11, 924-936.

38. Das, R.; Roy, A.; Dutta, N.; Majumder, H.K. Reactive oxygen species and imbalance of calcium homeostasis contributes to curcumin induced programmed cell death in Leishmania donovani. Apoptosis 2008, 13, 867-882.

39. Garcia, D.G.; Bianco, E.M.; Santos, M.C.B.; Pereira, R.C.; Faria, M.V.C.; Teixeira, V.L.; Burth, P. Inhibition of Mammal $\mathrm{Na}^{+} \mathrm{K}^{+}$-ATPase by diterpenes extracted from the Brazilian brown alga Dictyota cervicornis. Phytother. Res. 2009, 23, 943-947.

40. Ueda-Nakamura, T.; Attias, M.; Souza, W. Megasome biogenesis in Leishmania amazonensis: A morphometric and cytochemical study. Parasitol. Res. 2001, 87, 89-97.

41. Gadelha, F.R.; Thomson, L.; Fagian, M.M.; Costa, A.D.; Radi, R.; Vercesi, A.E. $\mathrm{Ca}^{2+}$-independent permeabilization of the inner mitochondrial membrane by peroxynitrite is mediated by membrane protein thiol cross-linking and lipid peroxidation. Arch. Biochem. Biophys. $1997,15,243-250$.

Samples Availability: Available from the authors.

(C) 2011 by the authors; licensee MDPI, Basel, Switzerland. This article is an open access article distributed under the terms and conditions of the Creative Commons Attribution license (http://creativecommons.org/licenses/by/3.0/). 